\title{
Pore types in the Blue Nile shale from the Blue Nile Basin using FE-SEM Method: Contribution to understanding gas storage
}

\author{
Monera Adam Shoieb1, Chow Weng Sum1, Mohd Suhaili Ismail1, Haylay Tsegab1 \\ and Tasneem Saleem2 \\ 1Department of Geosciences, Universiti Teknologi PETRONAS, 32610 Bandar Seri Iskandar, Perak, Malaysia \\ 2 Department of Geology, University of Khartoum, Khartoum, Sudan \\ *Corresponding author E-mail: monera_g03018@utp.edu.my
}

\begin{abstract}
Successful exploration and development of shale gas reservoirs have enabled the United States to ensure a predominantly domestic supply of gas for many years. Pore structures can significantly impact the mechanical and physical properties of the rock such as permeability, strength and durability. Understanding the microstructures of the rocks accurately and quantitatively is essential to petroleum engineering for evaluating and development of oil and gas, especially for the unconventional reserves with abundant interior nanoscale pores such as shale. The pore structure and morphology of twelve shale samples from the Blue Nile Formation in the Blue Nile Basin were carried out by apply-ing Field emission scanning electron microscopy (FESEM). FESEM is a widely used technique to examine pore structures in shale reser-voirs. The results of FESEM show that the Blue Nile shale samples have nanoscale pores which can be classified into four types: inter-particle pores, organic pores, intra-particle pores and micro-fractures. The common types are inter-particle pores between the clay particles and organic nano-pores. These pores are all large enough to store gas molecules.
\end{abstract}

Keywords: Blue Nile Basin, Blue Nile Formation, Shale gas, Pore structure.

\section{Introduction}

The recent popularity of unconventional gas shales as a future long-term energy source has, among other things, led to significant advances in understanding shale depositional and diagenetic processes, macroscale to microscale sedi-mentary structures, both coarse- and fine-scale stacking patterns of different lithofacies, and sequence- and para-sequence scale stratigraphy $[1,2]$. Organic-rich shales have previously been considered as source rocks and seals in a conventional petroleum system for many years [3]. The commercial production of shale gas and shale oil, however, has changed this idea and the mudrocks have received renewed attention in recent years because of their emer-gence as effective hydrocarbon reservoirs $[4,5]$. Shale gas plays an important role in fulfilling the increasing energy demand worldwide as it is one of the unconventional re-sources (Figure 1) [6].The interest in developing unconven-tional shale gas resources has supported the researches as-sociated with the characterization of shale formations, leading to understanding of shale's diagenetic processes, depositional and macroscale to microscale sedimentary structures [7] [8].

The characteristic of the pore system has significantly af-fect the accumulation, migration and production of natural gas [9].

Currently there are different methods which can be used for characterizing pore structures in shale formations, such as scanning electron microscopy (SEM) and field emission SEM (FESEM), Fluid injection techniques including mercu-ry intrusion porosimetry (MIP) using Fluid injection tech-niques and low pressure and N2/CO2 gas adsorption [10].

FE-SEM technique can be used directly to obtain partial picture of the pore structure characteristics, and can be further combined with statistical methods to quantitatively characterize the pore structures [11]. Different pore types can also influence geomechanical properties relevant to wellbore stability and hydrofracturing, as addressed by [12]. In this study twelve shale samples from the Blue Nile Formation in the Blue Nile Basin are use to document and classify the variety of pore types and to speculate on their potential control on gas storage by using Field emission electron microscope (FE-SEM).

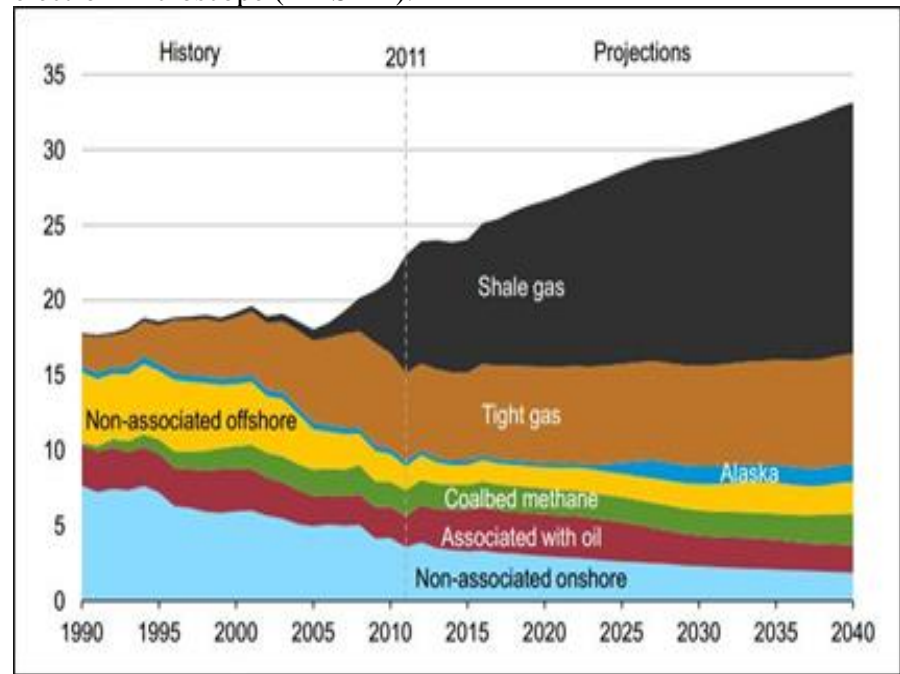

Figure 1. Unconventional gas as apportion of total U.S gas production [6]. 


\section{Geological Setting}

The Blue Nile Basin is located in South-East Sudan, $300 \mathrm{Km}$ south east of Khartoum (Figure 2). The tectonic history and structural development of the basin were re-ported By [13, 14]. The Blue Nile Rift Basin is analogous to the most important Sudan rifts which might be divided into 3 major phases (Figure 3). Every rifting phase consists of syn-rift strata and a sagging period; the primary rifting phase is pre-sedimentation phase involving the peneplana-tion of Neo-Proterozoic Basement rocks. This cycle is fol-lowed by sedimentation, including deposition of thick Mesozoic strata. The third rifting phase was created by the postsedimentation phase involving emplacement of ex-tensive EarlyLate Oligocene and Quaternary volcanic.

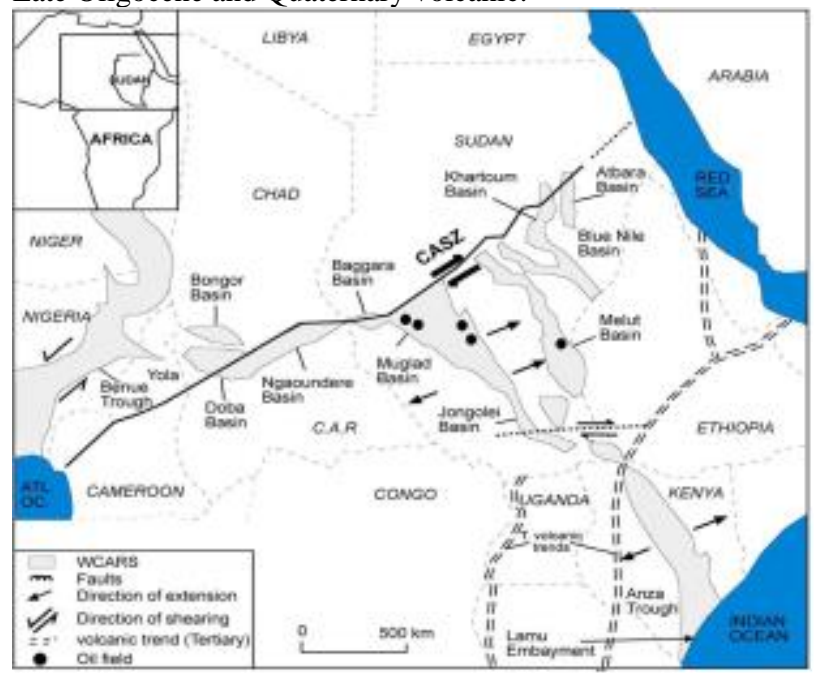

Figure 2. Tectonic model of the West and Central Af-rican Rift System [15].

Blue Nile Formation is the earliest stage in the evolution of the Blue Nile Basin; the age is from Early to Mid-Jurassic. This mainly consists of dark brown, thick shale, claystone interbedded with thin sandstone beds. Claystone are predominantly reddish brown, locally dark brown and dark gray. Sandstones present are predominantly very fine to fine grained, occasionally medium, off-white to light gray, often argillaceous and with a variable siliceous and calcareous cement. Therefore, the depositional environment is suggested to be lacustrine and marginal marine [18]. The Dinder Formation lies beneath the Blue Nile Formation and is dated as Mid Jurassic to Early Cretaceous in age. It represents the source rock all over the Blue Nile Basin and consists of three units: Dinder I, Dinder II and Dinder III Formations. Dinder Formation is generally arenaceous, sandier than the underlying Blue Nile Formation. The prominent lithology is shale/mudstone. Dinder-III Formation is featured by massive shale and mudstone, with minor thin sandstone and siltstone. The well-sorted sandstones are generally fine to very fine-grained and occasionally coarse-grained [19].

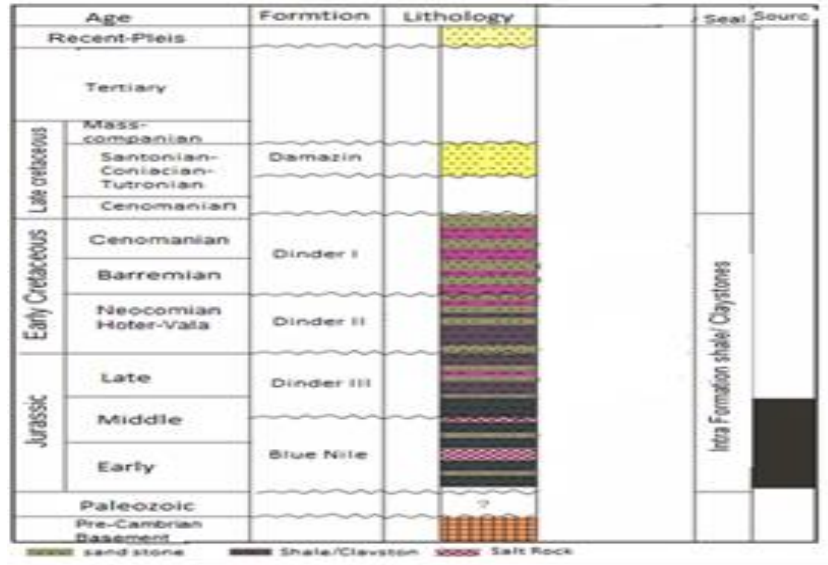

Figure 3. Regional stratigraphy of the Blue Nile Ba-sin, East Sudan, after [14].

\section{Material and methods}

A total of twelve cutting shale samples from two wells, Fa-rasha-1 and Tawakul-1, in the Blue Nile Basin. The sam-ples were collected from shale layers within the Blue Nile and Dinder Formation Figure (4), which located in the east and west of Dinder1 well, obtained from the Ministry of Petroleum in Sudan. The samples were sieve-washed using water to remove possible contaminations by drilling mud as oil-based mud was not detected. The samples have been selected for the Field emission scanning electron micro-scope (FE-SEM) technique, to get an idea into the nature of the pore structure. Field emission scanning electron micros-copy (FE-SEM) is an electron that describes the sample by scanning a beam of electrons. The electrons interact with the atoms that make up the sample producing signals that contain information about the sample surface topography, composition and properties - properties such as electrical conductivity. FE-SEM aims to look at the structure and shape of the samples.

\section{Results and Discussions}

\subsection{Mineralogy Bulk}

SEM-EDX analysis was carried out to image the mineral morphology and determine the chemical composition of the samples. Ten cutting samples from the Blue Nile For-mation were analyzed using SEM technique to study the structure of the minerals. Figure 4 show the images of shale samples from TW-1 and FR-1 well. In the SEM, the quartz appeared as rounded with small oval depressions. The presence of quartz is also confirmed by EDX techniques. The results show that the elemental composition of the shale samples in the well is dominated by silica and oxygen ( $\mathrm{Si}-\mathrm{O}$ ), and they have high peaks in the spectrum as shown in Figure 5.A. Also, the weight con-centration of these elements is high compared to the other elements present in the samples.

Kaolinite appeared as pseudohexagonal plates or books in the SEM result (Figure 4). The presence of kaolinite was also confirmed by EDX techniques (Figure 5.B). Results show that the elemental composition of the shale samples in the Blue Nile Formation is dominated by silica, oxygen and aluminum $(\mathrm{Al} 2 \mathrm{Si} 2 \mathrm{O} 5(\mathrm{OH}) 4)$ and the weight concentra-tion of $\mathrm{Si}$ and $\mathrm{Al}$ confirms their identification as kaolinite.

\subsection{Microscopic characteristics of pore}

The pore structure of shale has an important influence on the storage capability of shale gas [16]. Pore systems in rocks are generally affected by grain size, shape, sorting, packing, nature of cementing materials, by detrital and authigenic pore fillers, and by the previously imposed pres-sure and temperature history. These 
variables, through them influence on the pore structure, control important petro-physical properties such as porosity, permeability, irreduci-ble fluid saturation, formation resistivity factor, specific surface area, and velocities and attenuations of elastic waves. The microscopic characteristics of pore largely de-termine the performance of shale gas reservoirs [17]. Dur-ing the last few years, many researchers have discovered the pore features and able to determine many pore types in different shales by using of FESEM technique. Slatt et al [16] identified six varieties of pores, that includes organo-porosity which formed during the burial and maturation, inter-particle pores formed due to flocculation, intraparticle pores within mineral grains, intra-particle pores from organ-isms and micro-fractures based on study by Barnett and Woodford in [16] shales and micro-channels inside the shale matrix. Inter-particle pores, intra-particle pores, and organic matter pores are the three major types of the pore as classified by Loucks et al. [18]. In order to come up with an effective representation of pore structure characteristics of the Early Mid Jurassic shales in the Blue Nile Basin, 12 shale samples of the Blue Nile Formation were analyzed by using the Field Emission Scanning Electron Microscope (FE-SEM). The pore types that observed are fracture pores, intragranu-lar pores; intergranular pores and organic matter pores in the Blue Nile Formation shale samples (Figure 6). FESEM provides a complete picture about the real pore size distribution of shale samples than N2 adsorption or MIP [19].

\subsection{Microscopic characteristics of pore}

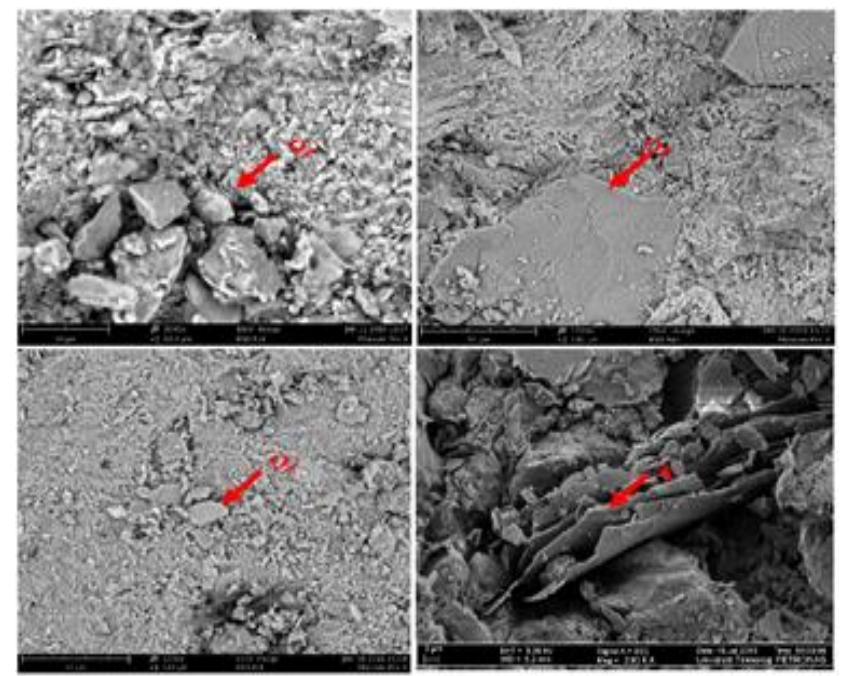

Figure 4: show the images of shale samples from TW-1 and FRwell.(A) Quartz appeared as rounded with small oval depressions. (B) Quartz appeared as large grain size. (C) Quartz appears as small grain size. (D) Kaolinite appeared as pseudohexagonal plates or books.
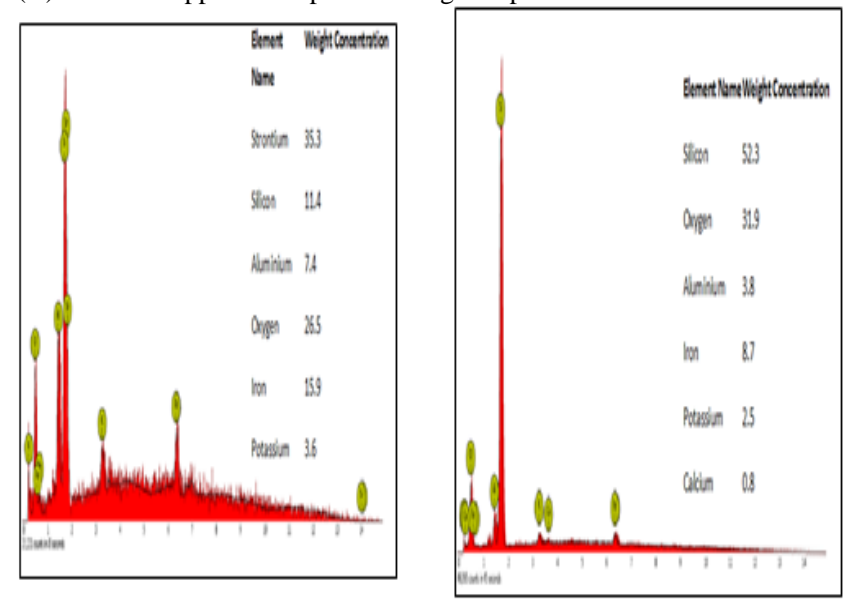

Figure 5. A. EDX Spectrum Analysis of TW-6 Shale Sample for quartz,B EDX Spectrum Analysis of TW-6 shale sample for kaolinite show the elemental composition of the shale sample.

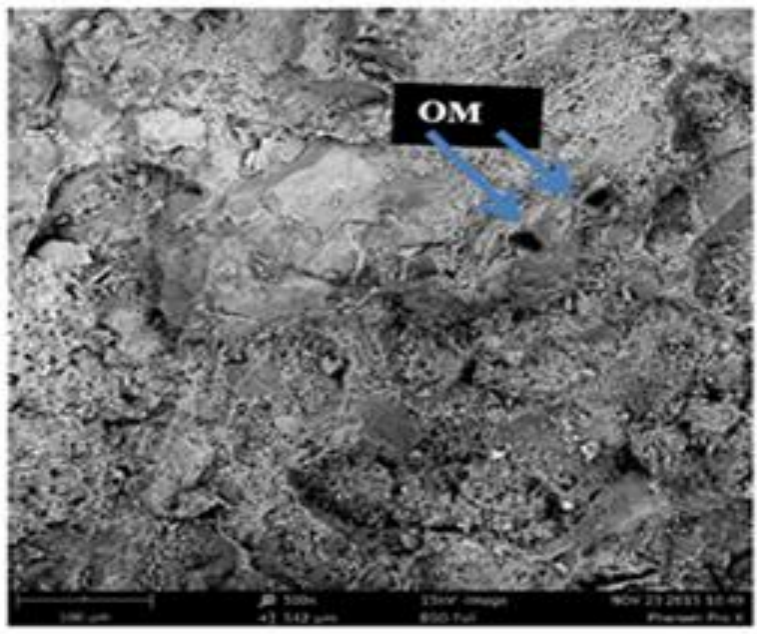

(a)

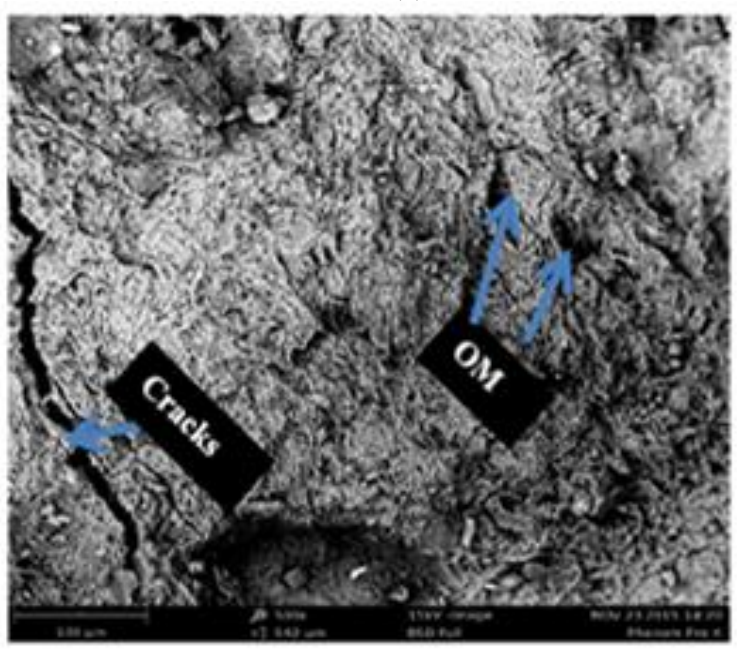

(b)

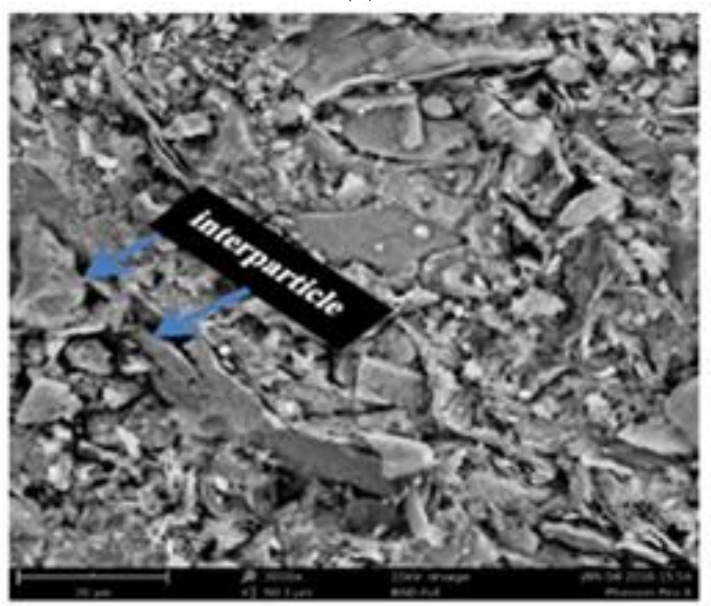

(C) 


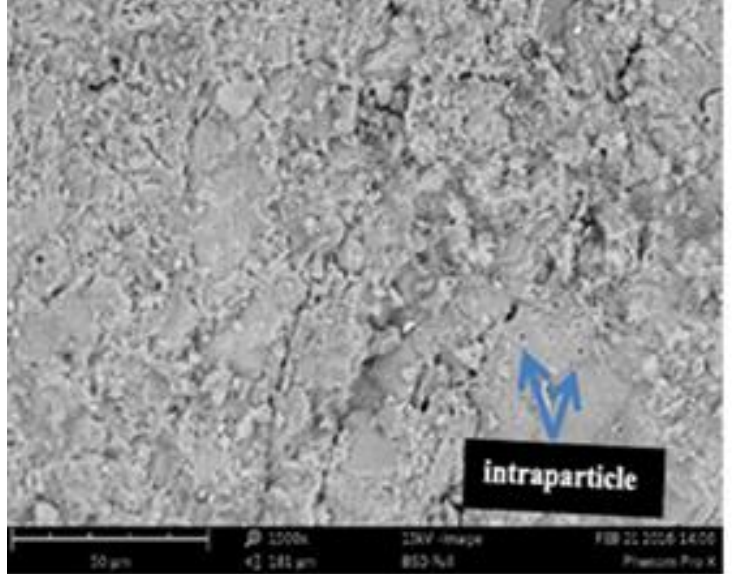

(d)

Figure 6. FE-SEM images of texture and pore types, A. Organic matter $(\mathrm{OM})$ pores observed in $\mathrm{TW}-2$ sample $\mathrm{B}$. Organic matter $(\mathrm{OM})$ pores observed and Wide fracture detected in sample TW-6, C. Inter particle pore within inorganic matrix , D. intra - particle within inorganic matrix.

\section{Conclusion}

In this paper, the pore characteristics of twelve shale sam-ples collected from the Blue Nile Formation in the Blue Nile Basin, were investigated and classified using Field emission electron microscope (FE-SEM). FE-SEM provided images useful for appreciating the complexity of the pore networks. Micro- and mesopores within organic matter and macropores, including interparticle pores between or within clay particles, fracture pore, intragranular pores and organ-ic matter pores are well developed in the Blue Nile For-mation. These pores are all large enough to store gas mole-cules.

\section{Acknowledgment}

The authors would like to acknowledge the support provid-ed for this publication from PRF Advanced Shale Gas Ex-traction Technology Using Electrochemical Methods pro-ject.

\section{References}

[1] Hickey, J.J. and B. Henk, Lithofacies summary of the Mississippian Barnett Shale, Mitchell 2 TP Sims well, Wise County, Texas. AAPG bulletin, 2007. 91(4): p. 437-443.

[2] Passey, Q.R., et al. From oil-prone source rock to gas-producing shale reservoir-geologic and petrophysical characterization of unconventional shale gas reservoirs. in International oil and gas conference and exhibition in China. 2010. Society of Petroleum Engineers.

[3] Hunt, J., Petroleum geology and geochemistry. 1996, New York, Freeman and Company.

[4] Montgomery, S.L., et al., Mississippian Barnett Shale, Fort Worth basin, north-central Texas: Gas-shale play with multi-trillion cubic foot potential. AAPG bulletin, 2005. 89(2): p. 155-175.

[5] Loucks, R.G., et al., Morphology, genesis, and distribution of nanometer-scale pores in siliceous mudstones of the Mississippian Barnett Shale. Journal of sedimentary research, 2009. 79(12): p. 848-861.

[6] Jarvie, D.M., Unconventional shale resource plays: Shale-gas and shale-oil opportunities. Texas Chtistian Unversity, Wordwide Geochemistry, 2008

[7] Loucks, R.G. and S.C. Ruppel, Mississippian Barnett Shale: Lithofacies and depositional setting of a deep-water shale-gas succession in the Fort Worth Basin, Texas. AAPG bulletin, 2007. 91(4): p. 579-601.

[8] Slatt, R.M. and N.D. Rodriguez, Comparative sequence stratigraphy and organic geochemistry of gas shales: Commonality or coincidence? Journal of Natural Gas Science and Engineering, 2012. 8 p. 68-84.
[9] Deng, H., et al., Improved pore-structure characterization in shale formations with FESEM technique. Journal of Natural Gas Science and Engineering, 2016. 35: p. 309-319.

[10] Clarkson, C.R., et al., Pore structure characterization of North American shale gas reservoirs using USANS/SANS, gas adsorption, and mercury intrusion. Fuel, 2013. 103: p. 606-616.

[11] Jochum, J., et al., Hydrocarbon-bearing fluid inclusions in calcitefilled horizontal fractures from mature Posidonia Shale (Hils Syncline, NW Germany). Ore Geology Reviews, 1995. 9(5): p. $363-$ 370.

[12] Slatt, R.M. and Y. Abousleiman, Multi-scale, brittle-ductile couplets in unconventional gas shales: Merging sequence stratigraphy and geomechanics. AAPG Search and Discovery, 2011. 80181.

[13] WNPOC., Dinder-1 well Petrophysical Re-evaluation Report, 2006.

[14] International, G.R.A.o.t.S.R.R., Well evaluation. unpublished, 1991: p. 2-56-2-57.

[15] Fairhead, J., Mesozoic plate tectonic reconstructions of the central South Atlantic Ocean: the role of the West and Central African rift system. Tectonophysics, 1988. 155(1-4): p. 181-191.

[16] Slatt, R.M. and N.R. O'Brien, Pore types in the Barnett and Woodford gas shales: Contribution to understanding gas storage and migration pathways in fine-grained rocks. AAPG bulletin, 2011 95(12): p. 2017-2030.

[17] Ambrose, R.J., et al. New pore-scale considerations for shale gas in place calculations. in SPE Unconventional Gas Conference. 2010. Society of Petroleum Engineers.

[18] Loucks, R.G., et al., Spectrum of pore types and networks in mudrocks and a descriptive classification for matrix-related mudrock pores. AAPG bulletin, 2012. 96(6): p. 1071-1098.

[19] Shoieb, M.A., et al., Pore structure characterization of shale gas reservoirs, Blue Nile Basin, Sudan. 2017. 